\title{
Concentration of Bio-Ethanol through Cellulose Ester Membranes during Temperature-Difference Controlled Evapomeation
}

\section{Tadashi Uragami}

Department of Chemistry and Materials Engineering, Kansai University, Osaka, Japan; Development of Innovative Science and Technology, Kansai University, Osaka, Japan.

Email: uragami@kansai-u.ac.jp

Received July $4^{\text {th }}, 2011$; revised July 29 $9^{\text {th }}, 2011$; accepted August $25^{\text {th }}, 2011$.

\begin{abstract}
To evaluate the high-performance of membrane materials in the concentration of an aqueous solution of dilute bioethanol under temperature-difference controlled evapomeation (TDEV), asymmetric porous cellulose nitrate (CN) and cellulose acetate (CA) membranes were prepared by a phase inversion method. In the concentration of dilute ethanol under TDEV, these membranes showed a high permeation rate and high ethanol/water selectivity. In membranes with almost the similar pore size, the ethanol/water selectivity was considerably higher for the CN membrane than the corresponding CA membrane. This result suggested that the affinity between the membrane material and the permeant is an important factor in the separation selectivity.
\end{abstract}

Keywords: Bio-Ethanol, Concentration, Membrane, Cellulose Ester, Temperature-Difference Controlled Evapomeation

\section{Introduction}

Ethanol that can be produced by biomass fermentation is a clean energy source, but typically its concentration is about $10 \mathrm{wt} \%$ in aqueous solution. To use such an aqueous ethanol solution as an energy source, we need to concentrate the dilute solution by distillation. However, distillation requires a high energy input. If the dilute ethanol solution could be concentrated by ethanol/water selective membranes with high permeation rate and high ethanol selectivity, this would offer a significant energy saving.

We have been studying the permeation and separation characteristics of aqueous ethanol solutions passed through various hydrophilic and hydrophobic polymer membranes. Hydrophilic membranes can selectively remove water from aqueous solutions of high ethanol concentration [1-6], whereas hydrophobic membranes allow ethanol permeation from aqueous solutions of dilute ethanol [7-9].

We have developed evapomeation (EV) [10,11], as shown in Figure 1(b), as a new membrane separation technique which utilizes the advantages of pervaporation (PV) (see Figure 1(a)) while limiting its disadvantages.
We have also proposed temperature-difference controlled evapomeation (TDEV) [12-21] in which a temperature difference is established between the feed solution and the membrane surroundings as shown in Figure 1(c). Poly(dimethylsiloxane) [7,8] and modified poly(dimethylsiloxane) [9] membranes in TDEV showed high ethanol/water selectivity for aqueous solutions of dilute ethanol.

In this study, to evaluate membrane materials in the concentration of bio-ethanol in TDEV, we selected cellulose nitrate $(\mathrm{CN})$ and cellulose acetate $(\mathrm{CA})$ as membrane materials, which have different affinities for etha-

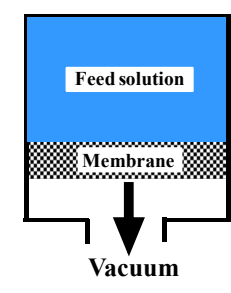

(a) PV

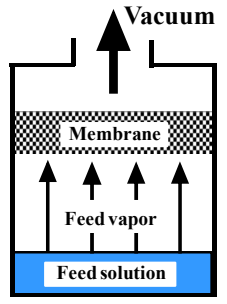

(b) $\mathbf{E V}$

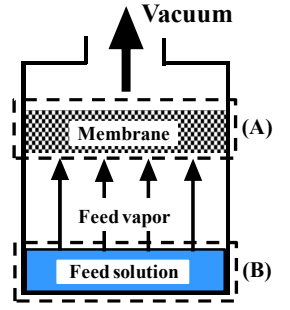

(c) TDEV
Figure 1. Schematics showing fundamental principles of PV, EV and TDEV. 
nol. Specifically, we describe in detail the permeation and separation characteristics of asymmetric porous $\mathrm{CN}$ and CA membranes during TDEV of an aqueous solution of dilute ethanol, and discuss the results in terms of the physical and chemical structures of the cellulose ester membranes.

\section{Experimental Section}

\subsection{Materials}

As membrane materials, cellulose nitrate $(\mathrm{CN})$ having a nitro content of $11.5 \%$ was obtained from Daicel Chemical Industry and recrystallized from methanol/water, and cellulose acetate (CA) having an acetyl content of $40.1 \%$ was obtained from Wako Chemical Indus- tries and recrystallized from acetone/water. Commercial methanol, 1,4-dioxane, and formamide from Wako Chemical Industries were used as solvents for casting solutions. Poly(ethylene glycol) (PEG) samples of 1000, 4000, and 6000 in average $M_{w}$ were obtained by Sanyo Chemical Industries for use as feed solutes in ultrafiltration experiments.

\subsection{Preparation of Asymmetric Porous $\mathrm{CN}$ and CA Membranes}

The asymmetric porous membranes were prepared by a phase-inversion method $[22,23]$. The casting solutions of the $\mathrm{CN}$ and $\mathrm{CA}$ membranes were consisted of $\mathrm{CN}$ (13 $w t \%$ ) and a mixture of methanol and 1,4-dioxane (as a non-solvent additive), and CA (13 wt\%) and a mixture of 1,4-dioxane and formamide (as a non-solvent additive), respectively. The non-solvent additives in the casting solutions are selected as poor solvents for the membrane materials. Asymmetric porous $\mathrm{CN}$ and $\mathrm{CA}$ membranes were made by pouring the casting solutions onto a glass plate, drawing a blade across the plate, allowing the solvent to evaporate for $10 \mathrm{sec}$ at $25^{\circ} \mathrm{C}$, and immersing the glass plate together with the membrane into cold water $\left(6^{\circ} \mathrm{C}-7^{\circ} \mathrm{C}\right)$ as a gelation medium.

\subsection{Permeation Measurements}

The apparatus for the TDEV experiments is described in a previous paper $[7,8]$. Figure 2 shows the permeation cell for the TDEV experiments. The TDEV experiments were performed by maintaining the temperature of the feed solution at $40^{\circ} \mathrm{C}$ and changing the temperature of the membrane surroundings while maintaining a pressure of $665 \mathrm{~Pa}$ at the downstream side. The ethanol concentrations in the feed solution and permeate were measured using gas chromatography (Shimadzu GC-9A).

\subsection{Scanning Electron Microscopy (SEM)}

Asymmetric porous $\mathrm{CN}$ and CA membranes were coated

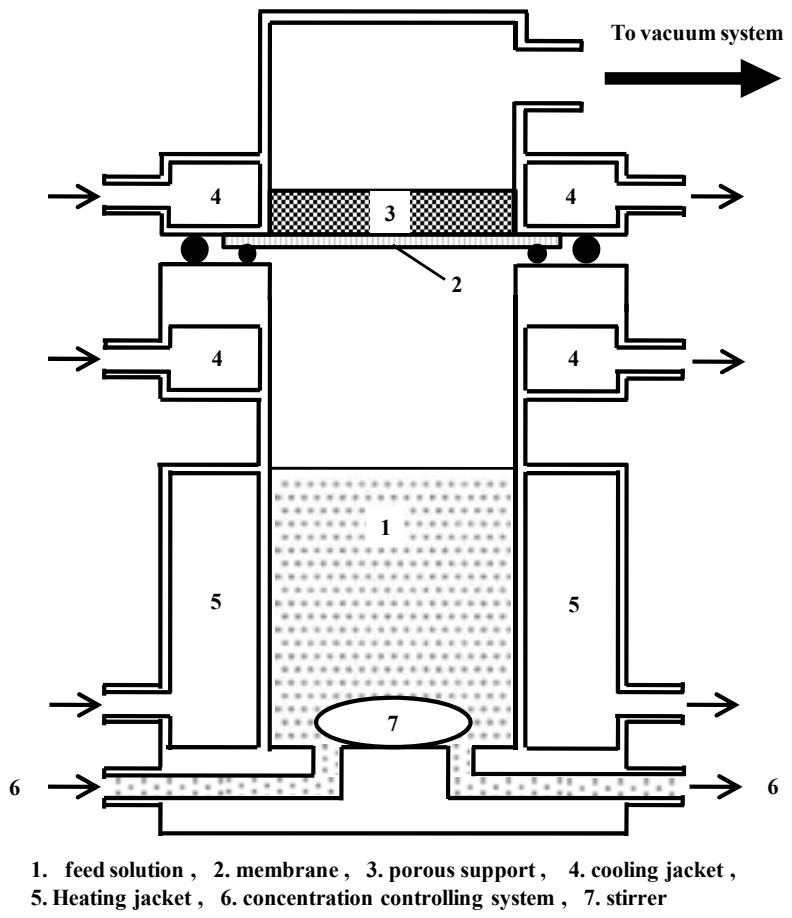

Figure 2. Permeation cell for TDEV.

with a layer of evaporated gold and the lyophilized membranes were observed through a scanning electron microscope (Japan Electron Optics, JEOL 100CX).

\subsection{Determination of Average Pore Size of Asymmetric Porous Membranes}

Porous membranes are known [24-26] to be subject to complex hydro-dynamic flow through pores of various sizes, and often a general mathematical analysis is used. In general, when a viscous liquid flows through a narrow pore, the flux of liquid, $\bar{u}$, is represented by the HagenPoiseuille equation [24]:

$$
\bar{u}=Q / \rho=\Delta p g_{c} r^{2} / 32 l \eta
$$

where $r$ is the pore diameter, $l$ is the length of the pore (skin layer thickness), $\eta$ is the viscosity of the liquid, $\Delta p$ is the pressure difference between the upstream solution and the downstream side of the membrane, $\rho$ is the liquid density, $g_{\mathrm{c}}$ is the gravitational conversion factor, and $Q$ is the flux.

The permeation of liquid through the skin layer of asymmetric porous $\mathrm{CN}$ and $\mathrm{CA}$ membranes may be due to both diffusive and viscous flows. Therefore, in this case, the permeation rate $(P R)$ of the liquid does not correspond exactly to the flux $(Q)$ given in Equation (1). However, if we assume that the flow through the skin layer of asymmetric porous $\mathrm{CA}$ and $\mathrm{CN}$ membranes follows viscous flow, Equation (3) can be obtained from 
Equations (1) and (2), as

$$
\begin{gathered}
P R \propto 1 / \eta^{2} \\
P R=Q^{2}
\end{gathered}
$$

By substituting Equation (3) into Equation (1), the average apparent pore diameter in $\mathrm{CA}$ and $\mathrm{CN}$ membranes is given by

$$
r=\left(32 l r Q^{\prime} / \Delta p g_{c}\right)^{1 / 2}
$$

where $Q^{\prime}$ is $P R^{1 / 2}$, and $\gamma$ is $\eta / \rho$ (the kinetic viscosity).

The average apparent pore diameter in the skin layer of asymmetric porous $\mathrm{CA}$ and $\mathrm{CN}$ membranes can be estimated using Equation (4) and the permeation flux for water at various temperatures.

\subsection{Measurement of Contact Angle}

The contact angles of water and methylene iodide on the surface of asymmetric porous $\mathrm{CA}$ and $\mathrm{CN}$ membranes were measured by a contact angle meter (Erma, model G-1) at $25^{\circ} \mathrm{C}$. The contact angles, $\theta$, were determined from the advancing contact angle $(\theta a)$ and receding contact angle $(\theta r)$ by Equation (5) [27].

$$
\theta=\cos ^{-1}\{(\cos \theta a+\cos \theta r) / 2\}
$$

In this study, the surface free energy was obtained from the contact angles of water and methylene iodide using Equation (6), which was proposed by Owens et al., [28] as follows:

$$
\begin{aligned}
& \left\{(1+\cos \theta) \gamma_{l} / 2\right\}=\left(\gamma_{s}^{d} \gamma_{l}^{d}\right)^{1 / 2}+\left(\gamma_{s}^{p} \gamma_{l}^{p}\right)^{1 / 2} \\
& \gamma_{s}=\gamma_{s}^{d}+\gamma_{l}^{p}
\end{aligned}
$$

where $\gamma_{s}^{d}$ and $\gamma_{l}^{p}$ are the surface free energies of the solid and liquid, respectively, and $\gamma_{s}^{d}, \gamma_{s}^{p}, \gamma_{l}^{d}$ and $\gamma_{l}^{p}$ are the dispersion force components and polar force components of the surface free energies of the solid and liquid, respectively. The values for these components have been reported by Forkes [29,30].

\subsection{Determination of Amount of Bound Water in Membranes}

The amount of bound water in the asymmetric CA and $\mathrm{CN}$ membranes was measured using the water content of the membrane and the heat of fusion obtained from frozen water in the membrane, $\Delta H$, which was determined by differential scanning calorimetry (DSC) (Rigaku, TAS-200) based on reports by Frommer [31].

\subsection{Ultrafiltration}

Ultrafiltration experiments were performed by the method reported in a previous paper [32]. The effective membrane area active in the cell was $12.7 \mathrm{~cm}^{2}$. All experiments were for the short-run type. The rejection percentage $(R)$ is defined as

$$
R=\left(1-C_{t} / C_{f}\right) \times 100
$$

where $C_{f}$ is the starting feed concentration and $C_{t}$ is the concentration in the permeate after $t$ hours.

\section{Results and Discussion}

\subsection{Structure of $\mathrm{CN}$ and $\mathrm{CA}$ Membranes}

Figure 3 shows SEM images of cross sections of the CN and CA membranes formed by different amounts of the non-solvent additive in the casting solution. As can be seen from these images, the membrane structures are significantly influenced by the amount of non-solvent and the resulting membranes obtained from the wet method consist of a skin layer on the air side and a sponge layer on the glass-plate side. The examples shown are typical of asymmetric membranes.

\subsection{Average Pore Diameter in Skin Layer of Asymmetric Porous CN and CA Membranes}

Figure 4 shows the effects of the non-solvent additive in the casting solution on the average pore diameter of asymmetric cellulose ether membranes. As can be seen, as the amount of non-solvent is increased, the average pore diameter of the asymmetric CA membrane increases remarkably, whereas that of the asymmetric $\mathrm{CN}$ membrane hardly changes. These results suggest that the formamide added to the casting solution in preparation of the CA membrane is effective as a non-solvent in relation to CA. Consequently, more sponge like asymmetric CA membranes could be formed. In contrast, the 1,4-dioxane used in the preparation of the $\mathrm{CN}$ membrane does not

CN membranes
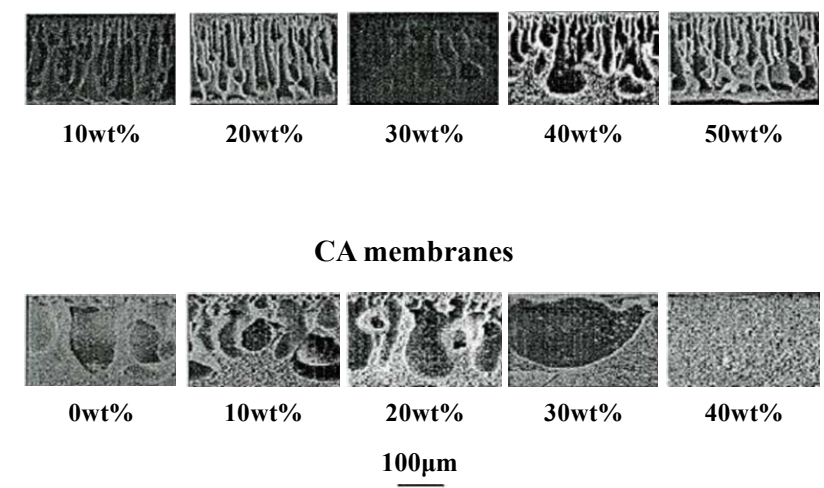

Figure 3. Effect of the amount of non-solvent additive in the casting solution on the cross-section structure of asymmetric CN and CA membranes as observed by SEM. 


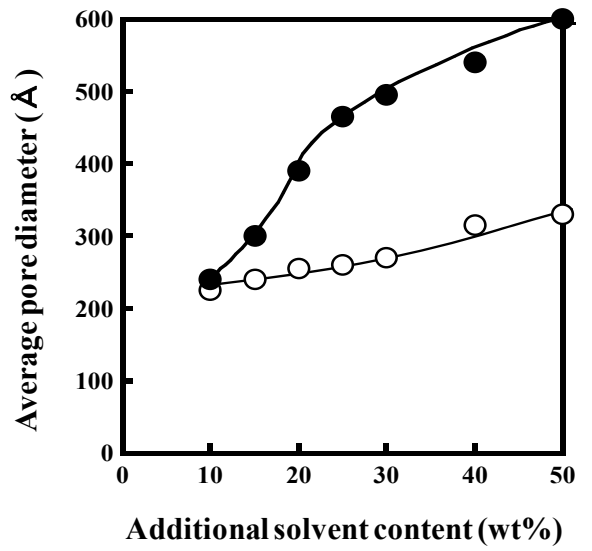

Figure 4. Effect of the amount of non-solvent additive in the casting solution on the average pore diameter in the skin layer of asymmetric $\mathrm{CN}(\mathrm{O})$ and $\mathrm{CA}(O)$ membranes.

appear to be effective as a non-solvent in relation to $\mathrm{CN}$.

\subsection{Surface Free Energy and Bound Water of $\mathrm{CA}$ and $\mathrm{CN}$ Membranes}

Table 1 shows the contact angles for water and methylene iodide on the surface skin layer of the asymmetric porous $\mathrm{CN}$ and $\mathrm{CA}$ membranes, along with the surface free energies calculated from these contact angles. The surface free energy for the $\mathrm{CN}$ membrane was lower than that for the CA membrane. This indicates that the $\mathrm{CN}$ membrane is more hydrophobic and consequently has a higher affinity for ethanol over water in an aqueous ethanol solution. Table 2 summarizes the amounts of bound water in the asymmetric porous $\mathrm{CN}$ and $\mathrm{CA}$ membranes as determined by DSC measurements. The amount of bound water in the $\mathrm{CN}$ membrane is found be considerably lower than that in the CA membrane. The results of the surface free energy and amount of bound water suggest that the $\mathrm{CN}$ membrane is more hydrophobic than the CA membrane.

\subsection{Effect of Temperature of Membrane Surroundings in TDEV}

Figure 5 shows the permeation and separation characteristics for an aqueous solution of $10 \mathrm{wt} \%$ ethanol passed through asymmetric $\mathrm{CN}$ and $\mathrm{CA}$ membranes during TDEV, in which the temperature of the feed was kept at $40^{\circ} \mathrm{C}$ and the temperature of the membrane surroundings was varied. As can be seen in the figure, when the temperature of the membrane surroundings is decreased, the ethanol concentration in the permeate increases but the permeation rate decreases in both the $\mathrm{CN}$ and CA membranes. Also both the ethanol concentration in the permeate and the permeation rate were higher in the $\mathrm{CN}$ membrane than in the CA membrane. The decrease in
Table 1. Contact angles and surface free energies of asymmetric $\mathrm{CN}$ and $\mathrm{CA}$ membranes.

\begin{tabular}{cccccc}
\hline \multirow{2}{*}{ membrane } & \multicolumn{3}{c}{ Contant angle (deg) } & \multicolumn{4}{c}{ Surface free energy $\left(\mathrm{erg} / \mathrm{cm}^{2}\right)$} \\
\cline { 2 - 6 } & $\mathrm{H}_{2} \mathrm{O}$ & $\mathrm{CH}_{3} \mathrm{O}$ & $\gamma^{d}$ & $\gamma^{p}$ & $\gamma^{h}$ \\
\hline $\mathrm{CA}$ & 56.2 & 29.8 & 35.2 & 16.4 & 51.6 \\
$\mathrm{CN}$ & 63.4 & 36.3 & 33.7 & 12.8 & 46.5 \\
\hline
\end{tabular}

Table 2. Amount of bound water in $\mathrm{CN}$ and $\mathrm{CA}$ membranes.

\begin{tabular}{cc}
\hline Membrane & $\begin{array}{c}\text { Amount of bound water } \\
\text { (mol water/mol repeated unit in polymer) }\end{array}$ \\
\hline $\mathrm{CA}$ & 2.58 \\
$\mathrm{CN}$ & 0.67 \\
\hline
\end{tabular}
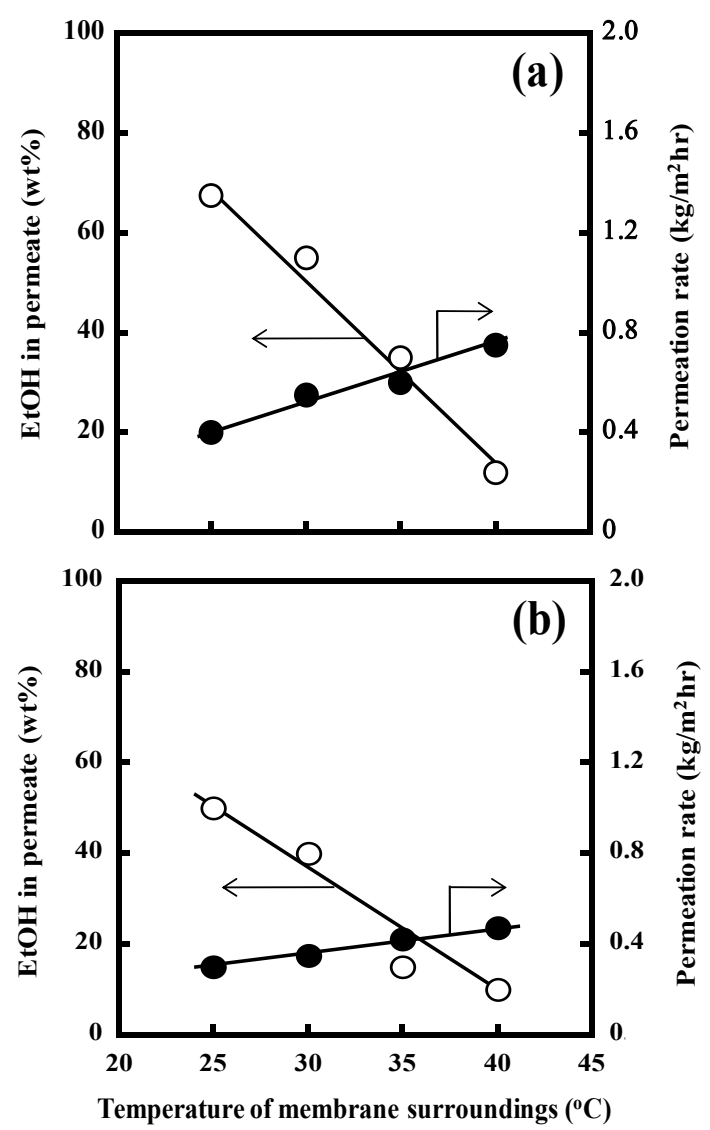

Figure 5. Effects of the temperature of the membrane surroundings on the permeation rate and ethanol concentration in the permeate for an aqueous solution of $10 \mathrm{wt} \%$ ethanol passed through asymmetric porous $\mathrm{CN}$ (a) and $\mathrm{CA}$ (b) membranes during TDEV. The temperature of the feed was kept at $40^{\circ} \mathrm{C}$ and that of the membrane surroundings was varied. The reduced pressure on the downstream side was $650 \mathrm{~Pa}$. The average pore diameters of asymmetric $\mathrm{CN}$ and CA membranes were 280 and $284 \AA$, respectively. 
permeation rate that occurs with a decrease in temperature of the membrane surroundings could be due to the fact that the increase in temperature difference between the feed and the feed vapor would lead to a decrease in the pressure difference between the feed side and the permeate side.

The increase in ethanol/water selectivity that occurs with decreasing temperature of the membrane surroundings in TDEV can be attributed to the tentative mechanism shown in Figure 6. That is, when water and ethanol molecules, vaporized from the feed solution, approach the lower-temperature membrane surroundings, the water vapor aggregates more readily than the ethanol vapor because the freezing point of water is much higher than that of ethanol. As such, the aggregated water molecules tend to liquefy as the temperature of the membrane surroundings becomes lower. On the other hand, because the membrane has a relatively high affinity to the ethanol molecules, they are absorbed within the pores of the membrane, and an absorbed layer of ethanol is formed in the initial stage of permeation. Consequently, the vaporized ethanol molecules may be able to permeate across the membrane by surface diffusion on the absorbed layer of the ethanol molecules within the pores.

Both mechanisms, aggregation of the water molecules and surface diffusion of the ethanol molecules in the pores, are considered to be responsible for the increase in the ethanol/water selectivity in TDEV. The level of increase in ethanol/water selectivity would then be related to the degree of water aggregation on the membrane surroundings and the thickness of the absorbed layer of ethanol within the pores, which are significantly gov-

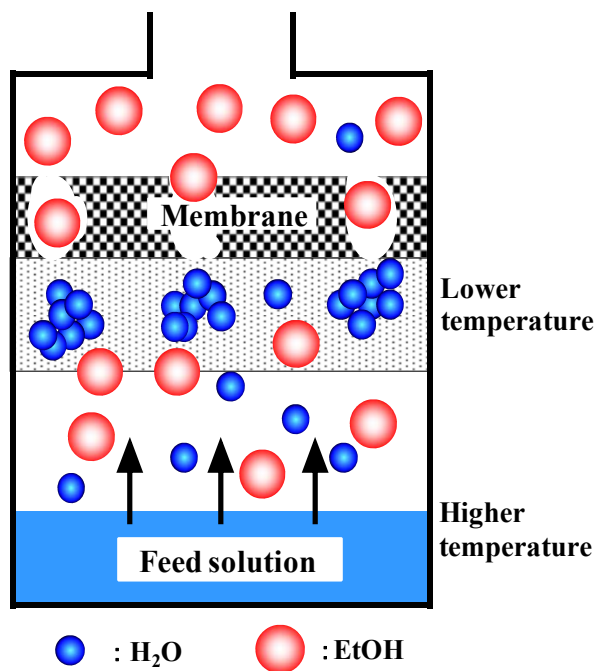

Figure 6. Tentative mechanism for the concentration of aqueous ethanol solutions through asymmetric porous $\mathrm{CN}$ and CA membranes in TDEV. erned by the temperature of the membrane surroundings. When the temperature of the membrane surroundings becomes lower, the degree of water aggregation and the thickness of the adsorbed layer of ethanol are increased, corresponding to an increase in the ethanol/water selectivity for aqueous ethanol solutions. The observation that both the ethanol concentration in the permeate and the permeation rate were higher in the $\mathrm{CN}$ membrane than in the CA membrane can be easily understood based on the results of the surface free energy and amount of bound water obtained in the $\mathrm{CN}$ and $\mathrm{CA}$ membranes as shown in Tables $\mathbf{1}$ and $\mathbf{2}$.

\subsection{Effect of Average Pore Diameter on Permeation and Concentration Characteristics in TDEV}

Figure 7 shows the permeation and concentration char-
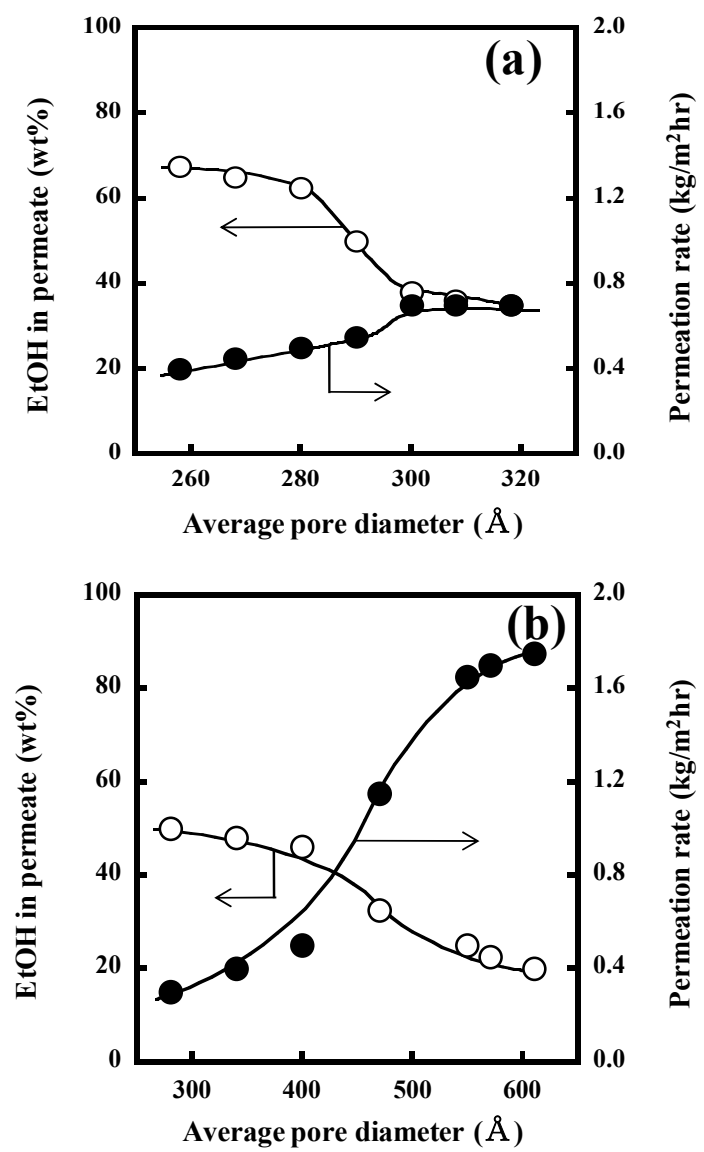

Figure 7. Effects of the average pore diameter in the skin layer of asymmetric $\mathrm{CN}$ (a) and $\mathrm{CA}$ (b) membranes on the permeation rate and ethanol concentration in the permeate for an aqueous solution of $10 \mathrm{wt} \%$ ethanol during $\mathrm{TDEV}$, in which the temperatures of the feed and the membrane surroundings were $40^{\circ} \mathrm{C}$ and $25^{\circ} \mathrm{C}$, respectively. The reduced pressure on the downstream side was $650 \mathrm{~Pa}$. 
acteristics for an aqueous solution of $10 \mathrm{wt} \%$ ethanol passed through asymmetric $\mathrm{CN}$ and $\mathrm{CA}$ membranes during TDEV as a function of the average pore diameter in the skin layer of asymmetric cellulose ester membranes. In the experiments, the temperature of the feed was $40^{\circ} \mathrm{C}$ and that of the membrane surroundings was $20^{\circ} \mathrm{C}$. As can be seen in both the $\mathrm{CN}$ and $\mathrm{CA}$ membranes, when the average pore diameter decreases, the ethanol concentration in the permeate increases and the permeation rate decreases. The decrease in permeation rate with decreasing average pore diameter is likely due to a decrease in the pore flow through these membranes.

\subsection{Chemical and Physical Structure of Asymmetric Porous Membranes}

Table 3 shows the effects of the chemical and physical structure on the permeation rate and ethanol concentration in the permeate through asymmetric porous $\mathrm{CN}$ and CA membranes by TDEV for membranes with almost similar pore size and similar rejection values for some PEGs in ultrafiltration. These results suggest the physical structures of the $\mathrm{CN}$ and $\mathrm{CA}$ membranes are the same. As can be seen from the ethanol concentrations in the permeate in Table 3, it is found that the $\mathrm{CN}$ membrane has a higher ethanol/water selectivity than the CA membrane. This result can be attributed to the fact that the $\mathrm{CN}$ membrane is more hydrophilic than the CA membrane as mentioned above.

\section{Conclusions}

When asymmetric porous $\mathrm{CN}$ and $\mathrm{CA}$ membranes were applied to TDEV in the concentration of an aqueous ethanol solution, a high permeation rate and high ethanol/water selectivity were obtained. The characteristics of permeation and separation through the $\mathrm{CN}$ and $\mathrm{CA}$ membranes were significantly influenced by the temperature of the membrane surroundings. In the $\mathrm{CN}$ and

Table 3. Characteristics of asymmetric porous $\mathrm{CN}$ and $\mathrm{CA}$ membranes.

\begin{tabular}{ccc}
\hline & \multicolumn{2}{c}{ Membrane } \\
\cline { 2 - 3 } & $\mathrm{CN}$ & $\mathrm{CA}$ \\
\hline Average pore diameter $(\AA))$ & 280 & 284 \\
Rejection & & \\
PEG 1000 & 13 & 11 \\
PEG 4000 & 24 & 23 \\
PEG 6000 & 46 & 46 \\
EtOH in permeate & 61 & 48 \\
\hline
\end{tabular}

CA membranes, the ethanol/water selectivity was attributed to both aggregation of water molecules on the lower-temperature membrane surroundings and surface diffusion of the ethanol molecule via an absorbed layer of ethanol formed within the pores. The permeation rate and ethanol/water selectivity of the asymmetric porous membranes were significantly influenced by the degree of water aggregation, the thickness of the absorbed layer of ethanol and the pore size of the membrane. In this study, we have demonstrated that a high permeation rate and high ethanol/water selectivity can be achieved by applying porous membranes to TDEV. CN membranes, in particular, offer potential for selective separation of ethanol/water.

\section{REFERENCES}

[1] T. Uragami, T. Matsuda H. Okuno and T. Miyata, "Structure of Chemically Modified Chitosan Membranes and Their Characteristics of Permeation and Separation of Aqueous Ethanol Solutions," Journal of Membrane Science, Vol. 88, No. 2-3, 1994, pp. 243-251. doi:10.1016/0376-7388(94)87010-1

[2] T. Uragami, S. Kato and T. Miyata, "Structure of $N$-Alkyl Chitosan Membranes on Water-Permselectivity for Aqueous Ethanol Solution," Journal of Membrane Science, Vol. 124, No. 2, 1997, pp. 203-211.

[3] T. Uragami, M. Takuno and T. Miyata, "Evapomeation Characteristics of Cross-linked Quaternized CHITOSAN Membranes for the Separation of an Ethanol/Water Azeotrope," Macromolecular Chemistry and Physics, Vol. 203, No. 9, 2002, pp. 1162-1170. doi:10.1002/1521-3935(200206)203:9<1162::AID-MAC P1162>3.0.CO;2-Q

[4] T. Uragami, Y. Tanaka and S. Nishida, "Permeation and Separation under High Temperature and High Pressure for Ethanol/water Vapors through Cross-Linked Quarternized Chitosan Composite Membranes," Desalination, Vol. 147, No. 1-3, 2002, pp. 449-454. doi:10.1016/S0011-9164(02)00642-2

[5] T. Uragami, S. Yamamoto and T. Miyata, "Dehydration from Alcohols by Polyion Complex Cross-Linked Chitosan Composite Membranes during Evapomeation," Biomacromolecules, Vol. 4, No. 1, 2003, pp. 137-144. doi: $10.1021 / \mathrm{bm} 0256420$

[6] T. Uragami, T. Katayama, T. Miyata H. Tamura, T. Shiraiwa and A. Higuchi, "Dehydration of an Ethanol/Water Azeotrope by Novel Organic-Inorganic Hybrid Membranes Based on Quaternized Chitosan and Tetraethoxysilane," Biomocrmolecules, Vol. 5, No. 4, 2004, pp. 1567-1574. doi: $10.102 / \mathrm{bm} 0498880$

[7] T. Uragami and T. Morikawa, "Permeation and Separation Characteristics for Aqueous Alcoholic Solutions by Evapomeation and Pervaporation through Polystyrene Membranes," Makromolekule Chemie, Rapid Communication, Vol. 190, No. 2, 1989, pp. 399-404. 
[8] T. Uragami and T. Morikawa, "Permeation and Separation Characteristics of Alcohol-Water Mixtures through Poly(Dimethyl Siloxane) Membrane by Pervaporation and Evapomeation," Journal of Applied Polymer Science, Vol. 44, No. 11, 1992, pp. 2009-2018. doi:10.1002/app.1992.070441116

[9] T. Uragami and H. Shinomiya, "Concentration of Aqueous Alcoholic Solutions through a Modified Silicone Rubber Membranes by Pervaporation and Evapomeation," Makromoekulare Chemie, Vol. 192, No. 10, 1991, pp. 2293-2305. doi:10.1002/macp.1991.021921009

[10] T. Uragami, M. Saito and K. Takigawa, "Comparison of Permeation and Separation Characteristics for Aqueous Alcoholic Solutions by Pervaporation and New Evapomeation Methods through Chitosan Membranes," Makromolekulare Chemie, Rapid Communication, Vol. 9, No. 5, 1988, pp. 361-365. doi:10.1002/marc.1988.030090513

[11] T. Uragami and M. Saito, "Analysis of Permeation and Separation Characteristics and New Technique for Separation of Aqueous Alcoholic Solutions through Alginic Acid Membranes," Separation Science Technology, Vol. 24, No. 7-8, 1989, pp. 541-554.

[12] T. Uragami, "Separation of Aqueous Organic Liquid Solutions through Polymer Membranes," Desalination, Vol. 90, No. 1-3, 1993, pp. 325-334. doi:10.1016/0011-9164(93)80184-O

[13] T. Uragami, "Concentration of Aqueous Ethanol Solutions by Porous Poly(Dimethylsiloxane) Membranes during Temperature-Difference Controlling Evapomeation," Desalination, Vol. 193, No. 1-3, 2006, pp. 335-343. doi:10.1016/j.desal.2005.09.026

[14] T. Uragami, "Structural Design of Polymer Membranes for Concentration of Bio-Ethanol," Polymer Journal, Vol. 40, No. 6, 2008, pp. 485-494. doi:10.1295/polymj.PJ2008015

[15] N. Işiklan and O. Şanli, "Permeation and Separation Characteristics of Acetic Acid/Water Mixtures through Poly (Vinyl Alcohol-G-Itaconic Acid) Membranes by Pervaporation, Evapomeation, and Temperature-Difference Evapomeation," Journal Applied Polymer Science, Vol. 93, No. 5, 2004, pp. 2322-2333. doi:10.1002/app.20710

[16] N. Işiklan and O. Şanli, "Permeation and Separation Characteristics of Acetic Acid-Water Mixtures through Poly(Vinyl Alcohol)/Malic Acid Membranes by Evapomeation and Temperature Difference Controlled Evapomeation," Separation Science and Technology, Vol. 40, No. 5, 2005, pp. 1077-1082.

[17] N. Işiklan and O. Şanli, "Permeation and Separation Characteristics of Acetic Acid-Water Mixtures through Poly (Vinyl Alcohol)/Malic Acid Membranes by Evapomeation and Temperature Difference Controlled Evapomeation," Separation Science and Technology, Vol. 40, No. 5, 2005, pp. 1083-1101. doi:10.1081/SS-200048179

[18] G. Asman and O. Şanli, "Separation of Acetic Acid-Water Mixtures through Poly(Vinyl Alcohol)/Poly(Acrylic Acid) Alloy Membranes by Using Evapomeation and Temperature Difference Evapomeation Methods," Sepa- ration Science and Technology, Vol. 41, No. 6, 2006, pp. 1193-1209. doi:10.1080/00497870600636928

[19] G. Asman and O. Şanli, "Using Poly(Vinyl Alcohol-G-4Vinyl Pyridine) Membranes by Pervaporation and Temperature Difference Evapomeation Techniques," Journal Applied Polymer Science, Vol. 100, No. 2, 2006, pp. 13851394. doi:10.1002/app.23676

[20] G. Asman and O. Şanli, "Separation Characteristics of Acetic Acid-Water Mixtures by Using Poly(Vinyl Alcohol-G-4-Vinyl Pyridine) Membranes by Pervaporation and Temperature Difference Evapomeation Techniques," Journal of Applied Polymer Science, Vol. 100, No. 3, 2006, pp. 2030-2039. doi:10.1002/app.22613

[21] S. E. Kondolot and O. Şanli, "Separation Characteristics of Dimethylformamide/Water Mixtures through Alginate Membranes by Pervaporation, Vapor Permeation and Vapor Permeation with Temperature Difference Methods," Separation Science and Technology, Vol. 41, No. 4, 2006, pp. 627-646. doi:10.1080/01496390500526789

[22] R. E. Kesting, "Synthetic Polymer Membranes," McGrawHill, Boston, 1971.

[23] R. E. Kesting, "Synthetic Polymer Membranes, A Structural Perspective," 2nd Edition, John Wiley \& Sons, New York, 1985.

[24] H. Yasuda, C. E. Lamazeand and A. Peterkin, "Diffusive and Hydraulic Permeabilities of Water in Water-Swollen Polymer Membranes," Journal of Polymer Science, Part $A$-2, Vol. 5, No. 6, 1971, pp. 1117-1131.

[25] U. Mertien, "Desalination by Reverse Osmosis," MIT Press, Cambridge, 1966. p. 22.

[26] T. Uragami, K. Maekawa and M. Sugihara, "Permeabilities of Alcohols and Hydrocarbons through Nylon 12 Membranes," Angewante Makromolekulare Chemie, Vol. 87, No. 1, 1980, pp. 175-193. doi:10.1002/apmc.1980.050870113

[27] K. Nakamae, T. Miyata N. Ootsuki, M. Okumura and K. Kinomura, "Surface Characterizations of Copolymer Films with Pendant Monosaccharides," Macromolecular Chemistry and Physics, Vol. 195, No. 6, 1994, pp. 1953-1963. doi:10.1002/macp.1994.021950606

[28] D. K. Owens and R. C. Wendt, "Estimation of the Surface Free Energy of Polymers," Journal of Applied Polmyer Science, Vol. 13, No. 8, 1969, pp. 742-1747. doi:10.1002/app.1969.070130815

[29] S. M. Fowkes, "Determination of Interfacial Tensions, Contact Angles, and Dispersion Forces in Surfaces by Assuming Additivity of Intermolecular Interactions in Surfaces," Journal of Physical. Chemistry, Vol. 66, No. 2, 1962, pp. 382-386. doi:10.1021/j100808a524

[30] S. M. Fowkes, "Additivity of Intermolecular Forces at Interfaces. I. Determination of the Contribution to Surface and Interfacial Tensions of Dispersion Forces in Various Liquids," Journal of Physical Chemistry, Vol. 67, No. 12, 1963, pp. 2538-2541. doi:10.1021/j100806a008

[31] M. A. Frommer and D. Lacent, "Freezing and Nonfreezing Water in Cellulose Acetate Membranes," Journal of 
Applied Polymer Science, Vol. 16, No. 5, 1972, pp. 12951303. doi:10.1002/app.1972.070160519

[32] T. Uragami and K. Fujino and M. Sugihara, "Concentration of Aqueous Polymer Solutions Using Porous Cellu- lose Acetate Membranes," Angewante Makromoekulare Chemie, Vol. 55, No. 1, 1976, pp. 29-42. doi:10.1002/apmc.1976.050550103 